Article

\title{
On the Impact of Particulate Matter Distribution on Pressure Drop of Wall-Flow Particulate Filters
}

\author{
Vicente Bermúdez, José Ramón Serrano, Pedro Piqueras * and Enrique José Sanchis \\ CMT-Motores Térmicos, Universitat Politècnica de València, Camino de Vera s/n, Valencia 46022, Spain; \\ bermudez@mot.upv.es (V.B.); jrserran@mot.upv.es (J.R.S.); ensanpac@mot.upv.es (E.J.S.) \\ * Correspondence: pedpicab@mot.upv.es; Tel.: +34-96-387-7650
}

Academic Editor: Antonio Ficarella

Received: 26 January 2017; Accepted: 24 February 2017; Published: 2 March 2017

\begin{abstract}
Wall-flow particulate filters are a required exhaust aftertreatment system to abate particulate matter emissions and meet current and incoming regulations applying worldwide to new generations of diesel and gasoline internal combustion engines. Despite the high filtration efficiency covering the whole range of emitted particle sizes, the porous substrate constitutes a flow restriction especially relevant as particulate matter, both soot and ash, is collected. The dependence of the resulting pressure drop, and hence the fuel consumption penalty, on the particulate matter distribution along the inlet channels is discussed in this paper taking as reference experimental data obtained in water injection tests before the particulate filter. This technique is demonstrated to reduce the particulate filter pressure drop without negative effects on filtration performance. In order to justify these experimental data, the characteristics of the particulate layer are diagnosed applying modeling techniques. Different soot mass distributions along the inlet channels are analyzed combined with porosity change to assess the new properties after water injection. Their influence on the subsequent soot loading process and regeneration is assessed. The results evidence the main mechanisms of the water injection at the filter inlet to reduce pressure drop and boost the interest for control strategies able to force the re-entrainment of most of the particulate matter towards the inlet channels' end.
\end{abstract}

Keywords: internal combustion engines; emissions; particulate matter; wall-flow particulate filter; pressure drop; soot distribution; particulate layer

\section{Introduction}

Pollutant regulations applying to compression ignition engines have focused on particulate matter emissions as one of the main pollutant emissions with which to deal. In Europe, particulate matter emissions have been restricted from $140 \mathrm{mg} / \mathrm{km}$ in Euro 1 to $4.5 \mathrm{mg} / \mathrm{km}$ in current Euro 6b. Besides stringent mass constraints, particulate number is also regulated by Euro $5 \mathrm{~b}$ applying both mass and number regulations also to direct injection spark ignition engines. Similar trends are found worldwide becoming wall-flow particulate filters in a required exhaust aftertreatment device already present in diesel engines and being progressively adopted in gasoline-powered vehicles.

The reason for the implantation of the wall-flow particulate filters is related to its high filtration efficiency in the whole range of particle size [1]. However, soot collection into and on the porous substrate produces a noticeable pressure drop, increasing as soot loading does. In standardized post-turbine placement, this pressure drop is multiplied by the turbine pressure ratio to define the increase in engine back-pressure directly damaging pumping work. The result is a non-negligible fuel consumption and carbon dioxide $\left(\mathrm{CO}_{2}\right)$ emission penalty [2]. In addition, the typically low temperature downstream of the turbine makes the use of active regeneration strategies necessary involving additional periodic fuel consumption. 
Although most of these drawbacks may be overcome with a pre-turbine Diesel Particulate Filter (DPF) placement [3], which enables conditions for passive regeneration and highly reduces DPF pressure drop impact on the fuel consumption penalty [4], the need for advanced boosting architectures to guarantee fast dynamic response [5] is postponing its further development. In the meantime, efforts are being driven to reduce aftertreatment volume by combining several abatement functions [6]. Thus, new devices, such as the Selective Catalytic Reduction Filter (SCRF) system, are gaining in interest. SCRF consists of the combination into a single wall-flow monolith of soot filtration and nitrogen oxides $\left(\mathrm{NO}_{x}\right)$ abatement capability by coating the porous substrate with a $\mathrm{NO}_{x}$ Selective Catalytic Reduction (SCR) catalyst [7]. Despite the potential improvement of this solution in terms of DPF passive regeneration, SCR light-off and conversion efficiency at low temperature, the combined chemical behavior of soot and $\mathrm{NO}_{x}$ is still suggesting doubts concerning the overlapping of temperature ranges, which can lead to a final slight loss of $\mathrm{NO}_{x}$ abatement and passive regeneration capability [8]. Regardless of the need for further understanding on new particulate filters with extended chemical functions, this kind of solution does not involve improvements concerning the fluid-dynamic behavior, i.e., pressure drop. The current context relies on cell geometry or porous wall optimization concepts, such as asymmetrical cell designs with different inlet channels geometry [9] or a two-layer substrate combining different micro-geometry properties [10]. These solutions contribute to partially mitigate the DPF impact on engine performance by changing the pressure drop to soot loading dependence. However, these parameters are still closely related, and the effects concerning fuel consumption are in the best case only slightly displaced to higher soot loading [11].

Under this context, pre-DPF water injection emerges as a technique able to reduce pressure drop with respect to a baseline DPF, making it independent of the particulate matter loading [12]. It leads to clear advantages in terms of fuel economy and $\mathrm{CO}_{2}$ emission. Secondarily, the particulate matter accumulation capacity is also increased. This feature is beneficial both in terms of ash through the reduction of maintenance requirements and soot, whose active regeneration can become exclusively controlled by soot mass loading instead of pressure drop criteria, thus avoiding an excessive regeneration temperature. Previous works [13] have hypothesized the water drag of the particulate matter towards the inlet channels end as the main cause of the pressure drop reduction without soot mass removal. This kind of restructuring is in agreement with findings about the influence of the ash deposition pattern along the inlet channels. While ash deposition mixed with soot on the particulate layer produces a great pressure drop [14], ash deposition in the rear end region leads to lower pressure drop. Rear end deposition of ash is explained by exhaust gas drag during long-term engine operation [15]. This kind of mechanism, i.e., soot restructuring during engine operation, would also contribute to explain why different pressure drops are usually found for the same engine operating conditions and soot loading under real driving operation. In the case of pre-DPF water injection, the drag process is forced by controlled periodic injection events affecting both soot and ash.

In this work, the impact of the particulate layer characteristics along the inlet channel is discussed. The analysis is guided by a computational study carried out with a one-dimensional gas dynamic code for wall-flow DPFs [16]. Parametric studies focus on the effect of the particulate layer thickness profile (soot mass distribution) combined with porosity to identify the solution domain that would provide the pressure drop obtained experimentally and its increased rate after pre-DPF water injection. The conclusions of the theoretical analysis are also supported by visualization of monolith substrates analyzed after pre-DPF water injection and in baseline conditions. As a final step, the influence of the particulate layer restructuring on the regeneration process is also explored by means of the modeling of experimental data obtained during active regeneration.

\section{Wall-Flow DPF Model}

The computational study performed in this work is based on the use of a wall-flow DPF model developed in previous works, which is next briefly described. The model is integrated into OpenWAM ${ }^{\mathrm{TM}}$ (Version 2.2, CMT-Motores Térmicos, Valencia, Spain), which is an open-source gas 
dynamics software developed at CMT-Motores Térmicos [17,18]. The model solves the conservation equations in a single pair of inlet and outlet channels assuming non-homentropic one-dimensional unsteady compressible flow:

- Mass conservation:

$$
\frac{\partial\left(\rho_{j} F_{j}\right)}{\partial t}+\frac{\partial\left(\rho_{j} u_{j} F_{j}\right)}{\partial x}=(-1)^{j} 4\left(\alpha-2 w_{p l} j\right) \rho_{j} u_{w_{j}}
$$

- Momentum conservation:

$$
\frac{\partial\left(\rho_{j} u_{j} F_{j}\right)}{\partial t}+\frac{\partial\left(\rho_{j} u_{j}^{2} F_{j}+p_{j} F_{j}\right)}{\partial x}-p_{j} \frac{d F_{j}}{d x}=-F_{w} \mu_{j} u_{j}
$$

- Energy conservation:

$$
\frac{\partial\left(e_{0 j} \rho_{j} F_{j}\right)}{\partial t}+\frac{\partial\left(h_{0 j} \rho_{j} u_{j} F_{j}\right)}{\partial x}=q_{j} \rho_{j} F_{j}+(-1)^{j} 4\left(\alpha-2 w_{p l j} j\right) h_{0 w} \rho_{j} u_{w_{j}}
$$

- Chemical species conservation:

$$
\frac{\partial\left(\rho_{j} Y_{j} F_{j}\right)}{\partial t}+\frac{\partial\left(\rho_{j} Y_{j} u_{j} F_{j}\right)}{\partial x}=(-1)^{j} 4\left(\alpha-2 w_{p l}\right) \rho_{j} u_{w j} Y_{j}
$$

In Equations (1)-(4), $j$ identifies the type of monolith channel $(0=$ outlet, $1=$ inlet $)$ and takes into account the existence of the particulate layer. Figure 1 shows schematically the way in which the DPF channels are discretized in the axial direction, as well as the cross-section of an inlet monolith channel identifying the main geometrical characteristics of the cell.
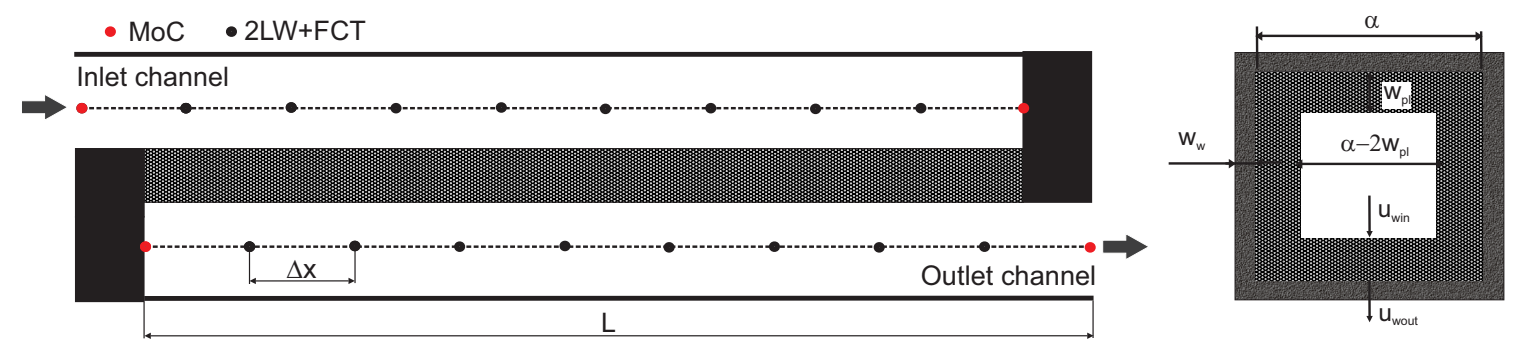

Figure 1. Scheme of the axial and cross-sections of Diesel Particulate Filter (DPF) channels.

The flow field of inlet and outlet channels is conditioned by the source terms related to flow across the porous media, which are governed by Darcy's equation applied along the particulate layer and the porous wall [16]. Thus, the filtration velocity at every axial node of the inlet channel can be calculated as a function of the pressure difference between the inlet and outlet channel, the cellular geometry and the permeability of every porous medium:

$$
u_{w_{\text {in }}}=\frac{p_{\text {in }}-p_{\text {out }}}{\frac{\mu_{\text {in }} w_{w}}{k_{w}} \frac{\rho_{\text {in }}\left(\alpha-2 w_{p l}\right)}{\rho_{\text {out }} \alpha}+\frac{\mu_{\text {in }}\left(\alpha-2 w_{p l}\right)}{2 k_{\text {pl }}} \ln \left(\frac{\alpha}{\alpha-2 w_{p l}}\right)}
$$

Accordingly, the filtration velocity corresponding to the outlet channel is then obtained considering the continuity equation between the inlet and outlet interface of the porous media:

$$
u_{w_{\text {out }}}=\frac{u_{w_{\text {in }}} \rho_{\text {in }}\left(\alpha-2 w_{\text {pl }}\right)}{\rho_{\text {out }} \alpha}
$$


The solution of the governing equations is obtained applying finite difference methods. In particular, the two-step Lax and Wendroff method (2LW) [19] adapted to porous medium channels is coupled with the Flux-Corrected Transport (FCT) technique [20]. The monolith channels are coupled to inlet and outlet volumes, which are included to account for the inertial pressure drop contribution because of flow contraction and expansion. The volumes are solved by a filling and emptying method and its connection to the monolith applying the Method of Characteristics (MoC) [21] adapted to solve the boundary conditions of inlet and outlet porous channels [22], as indicated in Figure 1.

According to Equation (5), the filtration velocity is dependent on the gas and porous media properties and the monolith meso-geometry. Both the porous wall and particulate layer permeabilities are obtained as a function of the porosity of the medium $(\varepsilon)$, the collector unit diameter $\left(d_{c}\right)$ and the slip-flow correction given by the Stokes-Cunningham Factor (SCF) as [23]:

$$
k=f(\varepsilon) d_{c}^{2} S C F
$$

In particular, the permeability of the porous wall is calculated considering that the soot penetration is only partial [24,25], so that Equation (7) is applied to a soot-loaded porous wall thickness and to the complementary one, which is considered to be kept fully clean:

$$
k_{w, e}=\frac{k_{w} k_{w_{0}}}{f_{w} k_{w_{0}}+\left(1-f_{w}\right) k_{w}}
$$

In Equation (8), $f_{w}$ represents the fraction of porous wall thickness where soot is collected; $k_{w_{0}}$ is the permeability of the clean porous wall; and $k_{w}$ is the permeability of the loaded porous wall. The properties of the soot loaded porous wall are obtained from clean conditions applying the packed spherical particles theory [26]. The diameter of the collector unit as soot is collected is obtained applying Equation (9)

$$
d_{c, w}=2\left(\frac{d_{c, w_{0}}^{3}}{8}+\frac{3 m_{s_{c e l l}}}{4 \pi \chi \rho_{s, w}}\right)^{\frac{1}{3}},
$$

where the apparent density of the collected soot is defined as the product of the density of soot aggregates of mean fractal dimension $\left(\rho_{s, w}\right)$ [27] and a shape factor $(\chi)$ representing the irregular deposition of the soot around the collector unit [23]. The variation of the collector unit diameter as the porous wall is loaded involves the change of the porosity. Knowing the cell unit diameter $\left(d_{c e l l, w}\right)$ from clean conditions,

$$
d_{c e l l, w}=\frac{d_{c, w_{0}}}{\left(1-\varepsilon_{w_{0}}\right)^{\frac{1}{3}}}
$$

the porosity under soot loading conditions is obtained as:

$$
\varepsilon_{w}=1-\frac{d_{c, w}^{3}}{d_{c e l l, w}^{3}} .
$$

Besides permeability, the change in porous wall properties also determines the fluid-dynamic field in the inlet channels as the soot loading takes places and governs the variation in filtration efficiency [28]. Brownian diffusion, interception and inertial deposition mechanisms are considered to compute the filtration efficiency of an isolated collector unit. Integrating within the packed bed control volume using the pore velocity as characteristic velocity for the particles due to the proximity among collectors [29], the filtration efficiency of the porous wall yields:

$$
E_{f, w}=1-e^{-\frac{3 \eta_{D R I}\left(1-\varepsilon_{w}\right) w_{w} f_{w} S_{c}}{2 \varepsilon_{w} d_{c}, w}}
$$


where $\eta_{D R I}$ is the filtration efficiency of an isolated collector unit due to the combination of the related collection mechanisms.

Once the transition from deep bed to cake filtration regimes is completed, the porous wall properties remain constant, and the particulate layer acts as a barrier filter. Thus, all collected soot is assumed to be deposited on the particulate layer, varying its thickness.

The amount of soot loading is determined every time-step accounting for the balance between filtrated and regenerated soot mass. Incomplete soot oxidation due to oxygen $\left(\mathrm{O}_{2}\right)$ and nitrogen dioxide $\left(\mathrm{NO}_{2}\right)$ is considered [30]. The variation of these reagents is solved separately across the particulate layer and the porous wall thickness for every reagent [31] as:

$$
\frac{\partial X_{n}}{\partial z}=-\frac{S_{p} k_{n} \alpha_{n}}{u_{w}}
$$

where subscript $n$ identifies $\mathrm{O}_{2}$ or $\mathrm{NO}_{2}, \mathrm{X}$ is the molar fraction, $S_{p}$ is the soot specific surface, $\alpha_{n}$ the stoichiometric coefficient and $k_{n}$ the kinetic constant, which is temperature dependent according to an Arrhenius-type equation. Knowing the depletion rate of every gaseous reagent across the particulate layer and the porous wall, the amount of regenerated soot per time-step and control volume can be obtained as:

$$
\begin{gathered}
\Delta n_{n}=\Delta X_{n} u_{w} A_{f} C_{g a s} \Delta t \\
m_{s, r e g}=M_{C}\left(-\frac{\Delta n_{\mathrm{NO}_{2}}}{\alpha_{\mathrm{NO}_{2}}}-\frac{\Delta n_{\mathrm{O}_{2}}}{\alpha_{\mathrm{O}_{2}}}\right)
\end{gathered}
$$

where $n$ represents the reagent moles, $A_{f}$ is the filtration area, $C_{g a s}$ is the gas concentration and $M_{C}$ is the soot molecular weight, which is assumed to correspond to carbon.

The rate of heat generated by the soot oxidation is included in the thermal balance solved in the porous substrate of every control volume in which the channels are axially discretized. The heat transfer model [32] is based on a bi-dimensional discretisation of the porous media between a pair of inlet and outlet channels. Besides the regeneration heat source, the model accounts for thermal inertia, convection gas to solid heat transfer, heat conduction across the substrate both in the axial and the tangential directions, as well as radial conduction towards the external canister, whose wall temperature is also computed taking into account heat transfer to the ambient environment.

\section{Experimental Setup}

The main details of the experimental setup and tests shown in this work are next briefly described. Further description can be found in [12]. In this work, the results of all tests to which a wall-flow DPF was subjected aimed to characterize its response against the use of pre-DPF water injection are presented. The main characteristics of the wall-flow DPF are summarized in Table 1, where it is identified as DPF \#A.

Table 1. Characteristics of wall-flow DPFs.

\begin{tabular}{lccc}
\hline & & \#A & \#B \\
& & {$[33]$} & {$[34]$} \\
\hline Diameter $(D)$ & $(\mathrm{mm})$ & 132 & 140 \\
Channel length $(L)$ & $(\mathrm{mm})$ & 200 & 230 \\
Honeycomb cell size $(\alpha)$ & $(\mathrm{mm})$ & 1.48 & 1.42 \\
Porous wall thickness $\left(w_{w}\right)$ & $(\mathrm{mm})$ & 0.31 & 0.46 \\
Cell density $(\sigma)$ & $(\mathrm{cpsi})$ & 200 & 180 \\
Porosity $\left(\varepsilon_{w_{0}}\right)$ & $(-)$ & 0.41 & 0.41 \\
Mean pore diameter $\left(d_{p_{w_{0}}}\right)$ & $(\mu \mathrm{m})$ & 12.1 & 18.55 \\
Permeability $\left(k_{w_{0}}\right)$ & $\left(\times 10^{-13} \mathrm{~m}^{2}\right)$ & 2.49 & 5.85 \\
\hline
\end{tabular}


The test campaign was conducted in a Euro 4 turbocharged diesel engine for passenger car use. The main characteristics of the engine are shown in Table 2 . The engine was installed in a completely instrumented test cell equipped with all of the required auxiliary facilities for its operation and control. Engine speed and torque were controlled by connecting the engine to an asynchronous dynamometer both under steady-state and transient operating conditions. The engine was also instrumented with sensors to measure the main magnitudes of operation, such as temperature and mean pressure along the intake and exhaust lines, air mass flow, fuel consumption and turbocharger speed. All of these data were completed with the electronic control unit and test cell parameters.

Table 2. Basic engine characteristics.

\begin{tabular}{ll}
\hline Type & HSDI Diesel Passenger Car \\
\hline Emission standards & Euro 4 \\
Displacement & $1997 \mathrm{~cm}^{3}$ \\
Bore & $85 \mathrm{~mm}$ \\
Stroke & $88 \mathrm{~mm}$ \\
Number of cylinders & 4 in line \\
Number of valves & 4 per cylinder \\
Compression ratio & $18: 1$ \\
Maximum power @ speed & $100 \mathrm{~kW} @ 4000 \mathrm{rpm}$ \\
Maximum torque @ speed & $320 \mathrm{Nm} @ 1750 \mathrm{rpm}$ \\
Aftertreatment & Close-coupled DOC + Underfloor DOC-DPF \\
\hline
\end{tabular}

In the particular case of the DPF, its pressure drop was measured by placing two piezoresistive transducers in the inlet and outlet cones of the DPF canning. The temperature was also measured in these locations with K-type thermocouples. The water was injected at the DPF inlet by means of a simple calibrated nozzle [12]. The assessment of the filtration efficiency was performed based on the particle concentration measurements upstream and downstream of the DPF with a TSI ${ }^{\mathrm{TM} E E P S}$ (Engine Exhaust Particle Sizer) spectrometer.

\subsection{Tests}

Several types of tests were performed in order to evaluate the pre-DPF water injection technique impact on the DPF performance. Every kind of test was repeated twice, thus comparing the test under baseline engine and DPF operation (without pre-DPF water injection) against the test in which pre-DPF water injection was applied.

Several DPF soot loading tests were performed to analyze the effects on the DPF pressure drop of the pre-DPF water injection technique under controlled conditions. In particular, a soot loading tests up to $30 \mathrm{~g}(11 \mathrm{~g} / \mathrm{L})$ in soot mass has been selected as a basis for the pressure drop and filtration efficiency study presented in this work. During all soot loading tests, the engine was run at $2500 \mathrm{rpm}$ and $28 \%$ in engine load being the exhaust gas recirculation rate $16 \%$.

After every soot loading test, the engine was subjected to different operating conditions in order to verify the pressure drop decrease and fuel economy benefit in a wider range of operation. The study covered driving cycles, motoring conditions at several engine speeds and steady-state operating conditions of low engine load. Finally, the DPF was regenerated applying an active regeneration based on an in-cylinder post-injection strategy. A regeneration process has been also selected for its modeling in the present work. In the selected test, the DPF was firstly loaded up to $60 \mathrm{~g}$ followed by two consecutive New European Driving Cycles (NEDC) before regeneration. This DPF loading process was repeated twice covering baseline operation and use of pre-DPF water injection, thus allowing the comparison of the corresponding regeneration processes. 


\section{Discussion of the Results}

\subsection{Pressure Drop}

Figure 2 shows the DPF pressure drop during the soot loading tests up to $30 \mathrm{~g}$ in soot mass. According to the experimental analysis presented in [12], the restructuring of the soot deposits in the particulate layer was hypothesized as the main cause to explain the decrease in pressure drop after every injection event and the capability to limit maximum pressure drop regardless of the amount of collected soot. This hypothesis has been analyzed in this work diagnosing the main particulate layer properties. A variety of soot mass distributions in the particulate layer with different effective porosity have been computed applying the wall-flow DPF model. The porous wall has been kept saturated with a soot penetration thickness of $2 \%$. These characteristics are based on the results obtained from the modeling of the soot loading process up to the first water injection event, which are described in [28]. Therefore, the objective has been to identify the main trends in particulate layer properties' variation that provide the pressure drop after a pre-DPF injection event.

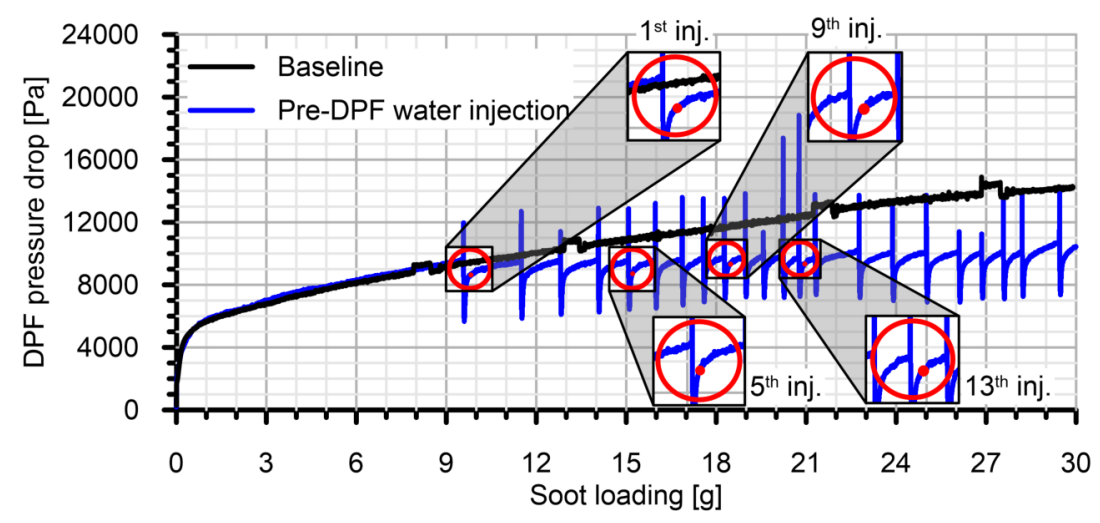

Figure 2. Soot loading test in DPF \#A defining the conditions of the parametric studies.

In particular, the pressure drop at the end of the injections marked with a red circle in Figure 2 has been analyzed. The selected pressure drop value is the one after the end of the thermal transient that follows a pre-DPF water injection. This value determines the benefit in pressure drop reduction [12]. For the sake of simplicity, the properties of all inlet channels have been assumed to be the same, which implies the assumption of a homogeneous water distribution within the monolith cross-section. Therefore, the results of the parametric study must be understood as lumped representative properties of the collected soot.

According to the results presented in [28] and as the boundary condition for the modeling work, the particulate layer porosity before the first water injection event is known to be 0.65 . This data were obtained assuming that the representative collector unit diameter in the particulate layer is that of the mode of the particle size distribution $(69 \mathrm{~nm})$. Nevertheless a range of particulate layer porosity from 0.4-0.97 has been considered in this work. It provides a wide range to analyze the possible effect of particulate layer compaction at the same time that the maximum values of porosity reported in the literature [35] have been covered.

Concerning the soot mass distribution, an increase of the particulate layer thickness has been assumed along the inlet channels till the plug end. In every axial location, the thickness of the particulate layer is assumed to be homogenous on all of the channel walls. Linear and parabolic laws to define the rate of thickness increase have been explored. In addition, the particulate layer thickness is assumed to be very thin and constant from the inlet cross-section up the a given distance from which the increasing thickness profile is imposed. This distance, which will be referred to as the onset of the soot mass distribution $\left(\delta_{p l}\right)$ from now on, has been also varied in order to determine its impact on the 
pressure drop. This study is based on the conclusions obtained from Scanning Electron Microscope (SEM) analysis [34]. Figure 3 shows SEM pictures corresponding to two different samples of DPF \#B, which was loaded with $44.6 \mathrm{~g}$. The pictures show the cross-section of an inlet channel at two different distances from the monolith entrance. One of the samples was subjected to a pre-DPF water injection. Both cases show that the penetration is very small, as concluded from experimental [25] and modeling [23] studies, just affecting the porous wall rugosity. On the one hand, the baseline sample shows a similar thickness of the soot cake both at the inlet and rear end. On the other hand, the case of the sample subjected to water injection shows an irregular thin particulate layer at the inlet region of the channel. The soot tends to be accumulated in the end region of the channel close to the plug. This is confirmed by Figure 4, which shows three pictures of the rear end ( $21.5 \mathrm{~cm}$ from monolith inlet) in different inlet channels. A clear random accumulation of soot layer fragments can be observed. Its effect can be assumed equivalent to a fast increase of the particulate layer thickness in this region, thus decreasing the inlet channel effective cross-section area.
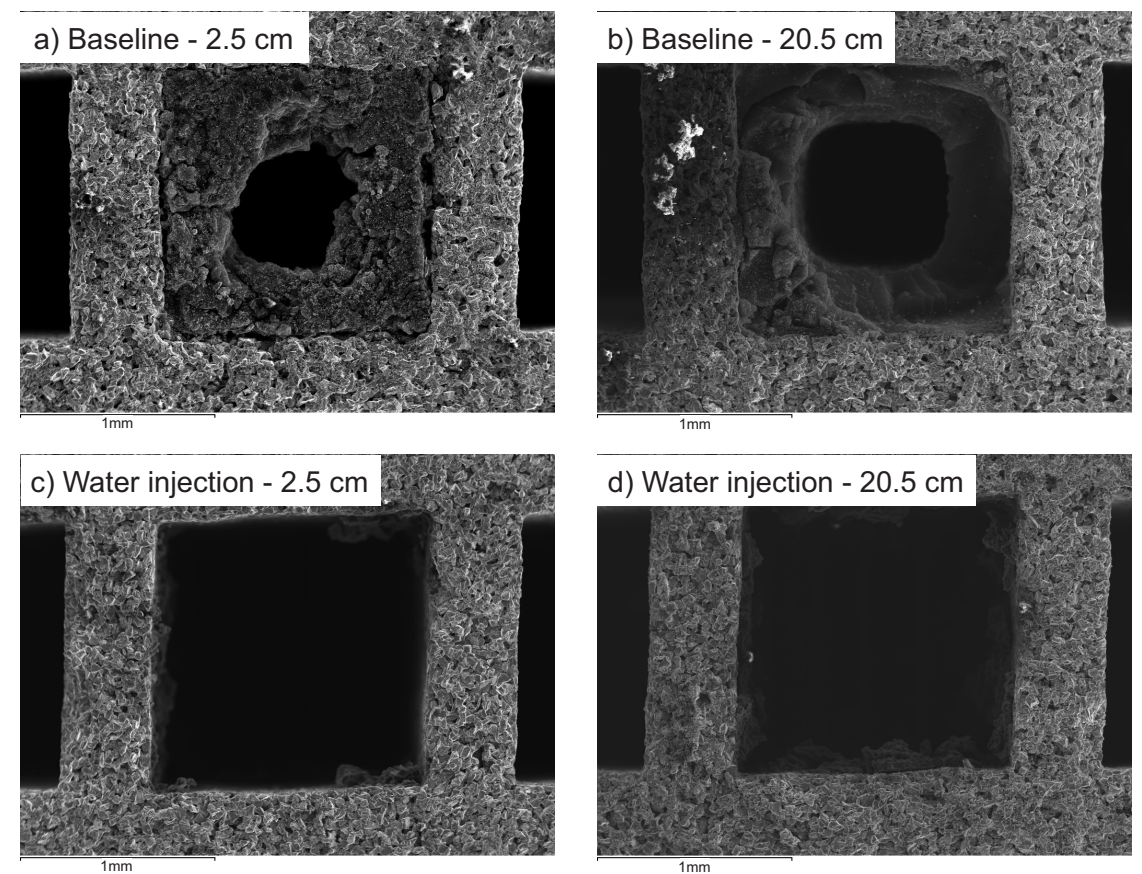

Figure 3. Scanning Electron Microscope (SEM) pictures of the cross-section of DPF \#B inlet channels with the same soot loading at different locations in baseline and after water injection conditions: (a) baseline at $2.5 \mathrm{~cm}$; (b) baseline at $20.5 \mathrm{~cm}$; (c) pre-DPF water injection at $2.5 \mathrm{~cm}$; (d) pre-DPF water injection at $20.5 \mathrm{~cm}$.
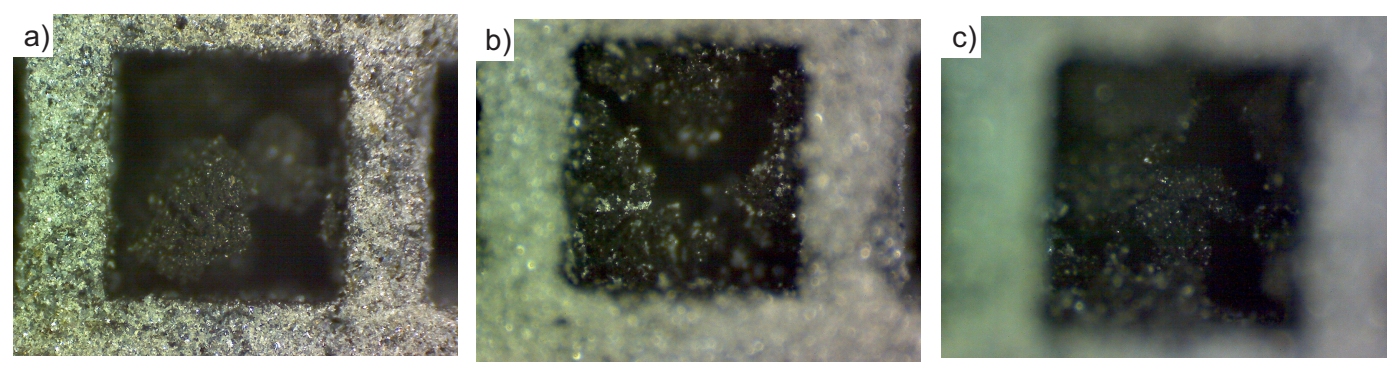

Figure 4. Pictures of soot agglomerates accumulation in the rear end of three inlet channels $(21.5 \mathrm{~cm}$ from monolith inlet) after water injection in DPF \#B. 
The swept-in particulate layer porosity and onset of the soot mass distribution provide an extensive family of particulate layer structures. Figure 5 a shows how the particulate layer porosity changes the soot thickness along the inlet channels. The grey dashed series represents the particulate layer thickness just before the first injection event, the particulate layer porosity being 0.65. In all remaining cases, the soot mass distribution is exactly the same, i.e., at a given point, the amount of soot is the same at any particulate layer porosity. In these examples, the onset of the soot mass distribution is at $\delta_{p l}=0.1 \mathrm{~m}$ from the inlet monolith cross-section imposing a parabolic profile. Therefore, the change in porosity is the responsible of the different cake thickness according to Equation (16):

$$
w_{p l, i}=\frac{\alpha_{i n}-\sqrt{\alpha_{i n}^{2}-\frac{m_{s, p l, i}}{\Delta x \rho_{p l}}}}{2}
$$

where subscript $i$ identifies the node of computation along the channel. The density of the particulate layer $\left(\rho_{p l}\right)$ is a function of the carbon density and the porosity of the particulate layer:

$$
\rho_{p l}=\rho_{C}\left(1-\varepsilon_{p l}\right)
$$
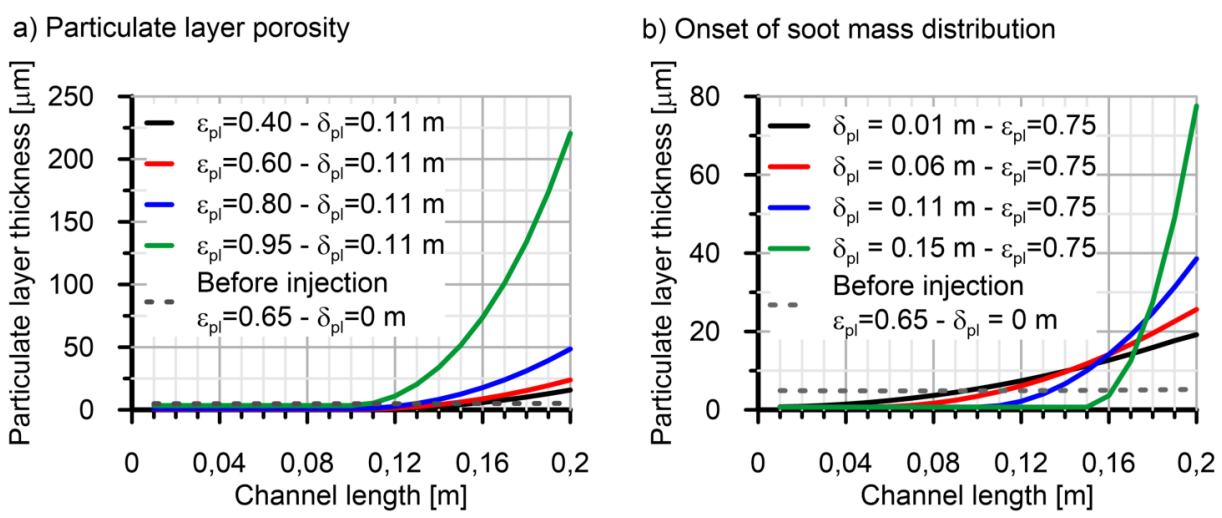

Figure 5. Effect of particulate layer porosity and soot mass distribution onset on the particulate layer thickness profile in DPF \#A.

Below a porosity of 0.6 , the particulate layer thickness is very thin along the whole channel. However, as the porosity increases, the thickness undergoes a faster growth, as clearly observed for 0.95 in porosity. The differences in thickness become evident from the very beginning of the soot mass distribution onset and increase towards the inlet channel rear end. In contrast to porosity, the onset of the soot mass distribution in the particulate layer, whose effect is represented in Figure 5b, gives rise to quite homogeneous cake thickness, most of the differences being concentrated in the rear end region. This is especially evident as the soot mass distribution is moved back, which produces a sharp rate of thickness increase from $0.15 \mathrm{~m}$ in the onset length.

The DPF pressure drop resulting from the parametric study imposing experimental inlet flow conditions and soot loading after the water injection is shown in Figure 6 for Injections 1, 5, 9 and 13. A parabolic soot mass distribution is considered in these computations. In all plots, the white line represents the solution domain corresponding to the experimental pressure drop value for every injection. 
a) Pressure drop after $1^{\text {st }}$ injection $[\mathrm{Pa}]$

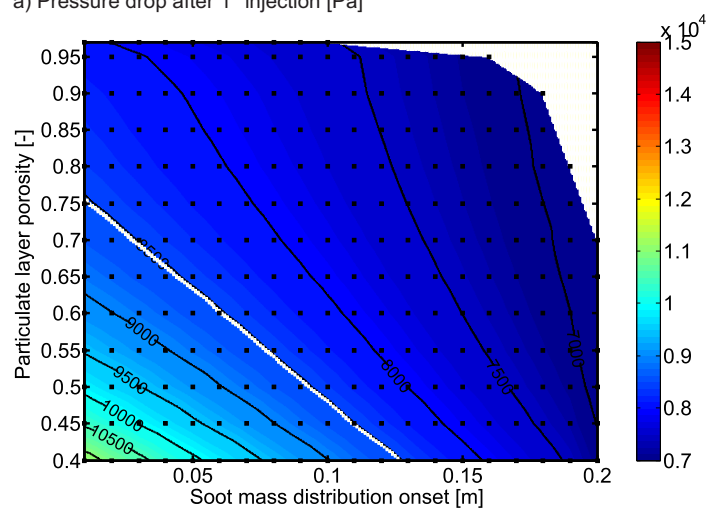

c) Pressure drop after $9^{\text {th }}$ injection $[\mathrm{Pa}]$

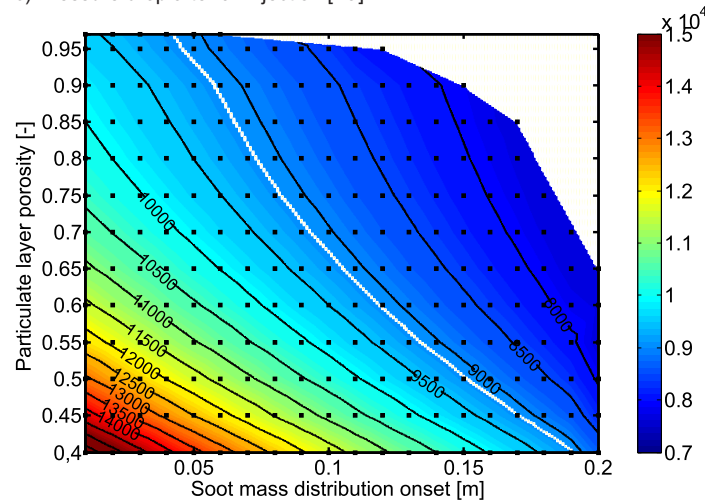

b) Pressure drop after $5^{\text {th }}$ injection $[\mathrm{Pa}]$

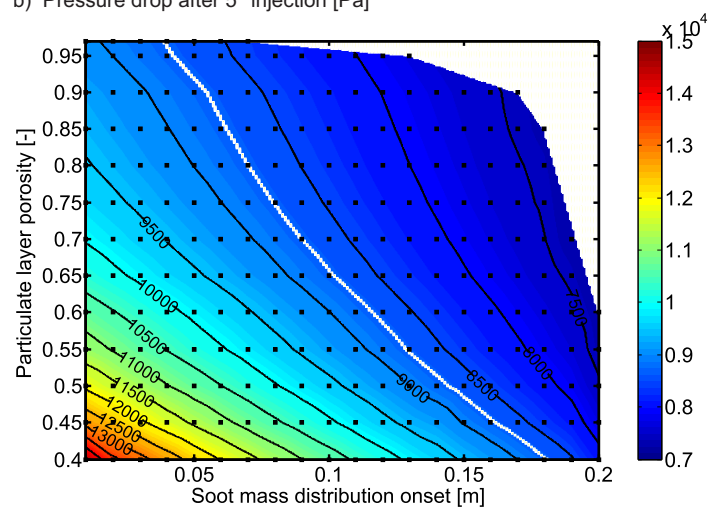

d) Pressure drop after $13^{\text {th }}$ injection $[\mathrm{Pa}]$

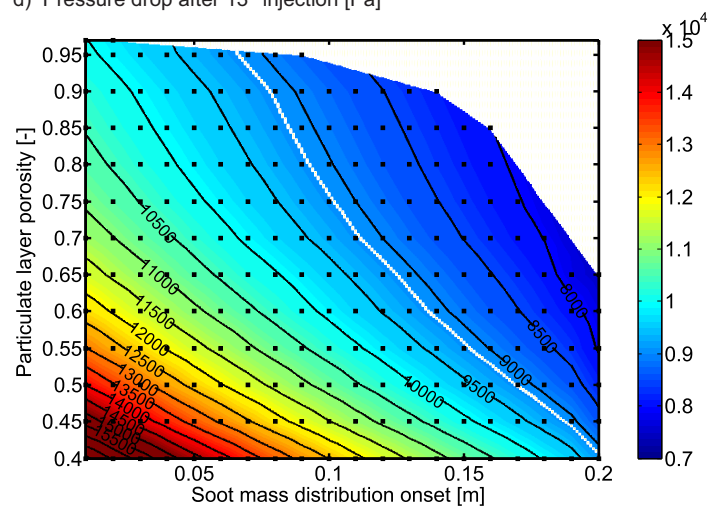

Figure 6. DPF pressure drop as a function of the particulate layer porosity and the soot mass distribution onset after different injection events in DPF \#A.

As observed in all cases, moving back the soot mass distribution onset provides an almost linear decrease of the pressure drop regardless of the particulate layer porosity. This is shown in Figure 7, which presents the pressure drop dependence on the onset of the soot mass distribution for the parabolic profile and different water injections. The maximum pressure drop is always found when the onset of the particulate layer is placed close to the monolith inlet. This means that the worst loading conditions of the DPF are determined by an homogeneous particulate layer along the whole channel, which is the natural profile towards soot loading processes' convergence [28]. These results evidence the interest for soot and ash accumulation in the rear end of the inlet channels. On the other hand, given any onset for the growth of the particulate layer thickness, the pressure drop decreases as the porosity increases. These kinds of conditions would be caused by an engine operating at high mass flow, thus at medium-low temperature, thus resulting in a high Peclet number [35]. In addition, the impact is greater in homogenous soot mass distribution and as soot loading increases. Higher soot loading correlates with the injection number according to Figure 2, i.e., the 13th water injection takes place at higher soot loading conditions.

Keeping as a reference a particulate layer porosity of 0.65, the analysis of the plots in Figure 6 reveals that the experimental pressure drop obtained in DPF \#A after the first pre-DPF water injection can be only attained provided that the particulate layer begins its growth several centimeters after the channel inlet $(\sim 4.5 \mathrm{~cm})$. This trend is more clear as the number of injections increases, even taking into account that the pressure drop after the thermal transient related to the injection event grows up from $8500 \mathrm{~Pa}-9200 \mathrm{~Pa}$. In the 13th water injection, the growth of the particulate layer should begin at $12.5 \mathrm{~cm}$ from the monolith inlet, assuming that the particulate layer porosity is kept in 0.65 . Therefore, the onset of the soot mass distribution is progressively moved towards the channel end as the amount of soot increases. This fashion in soot mass distribution in the particulate layer explains the need to increase the target pressure drop after the 13th water injection that was necessary to impose during 
the soot loading test shown in Figure 2. In order to ensure the effectiveness of the water injection technique [12], it is necessary to allow the particulate layer thickness to grow again along the inlet channels before to perform the next water injection. In addition, it is worth noting how the rear soot accumulation should be more intensive if the porosity of the particulate layer decreases as a result of a water compaction process. According to Darcy's law, this effect indicates that the permeability decrease caused by the porosity reduction has much more negative impact than the benefits brought by a thinner particulate layer. Figure 8 represents the particulate layer permeability as a function of the porosity, according to Equation (7). In contrast, the thickness is a function of the porosity, the soot distribution profile and, consequently, the axial location along the inlet channel, in agreement with Figure 5.
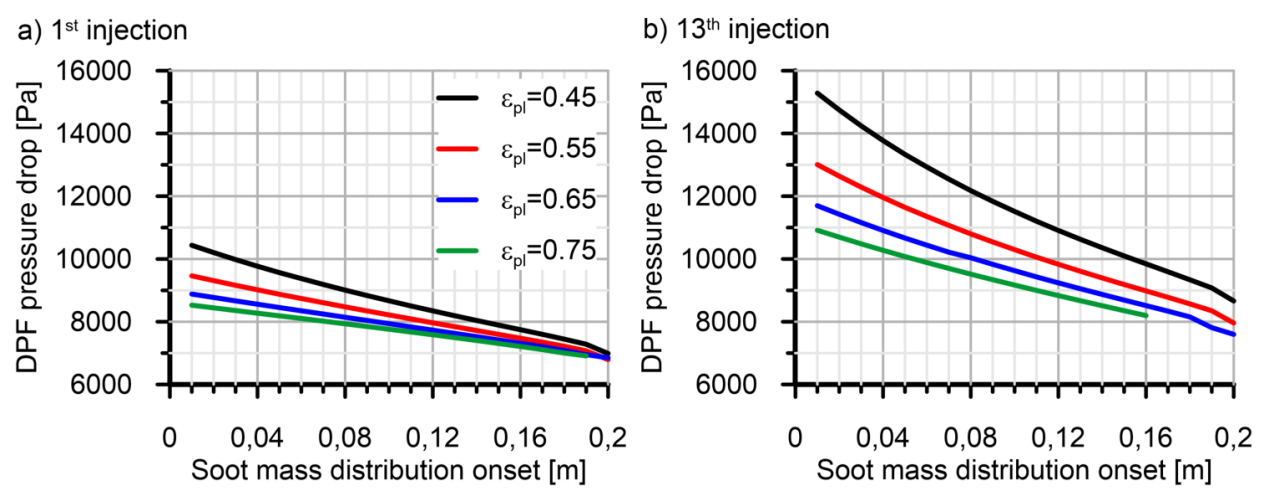

Figure 7. Impact of the onset of the soot mass distribution on the DPF pressure drop as a function of the particulate layer porosity and the soot mass loading (number of injections) in DPF \#A.

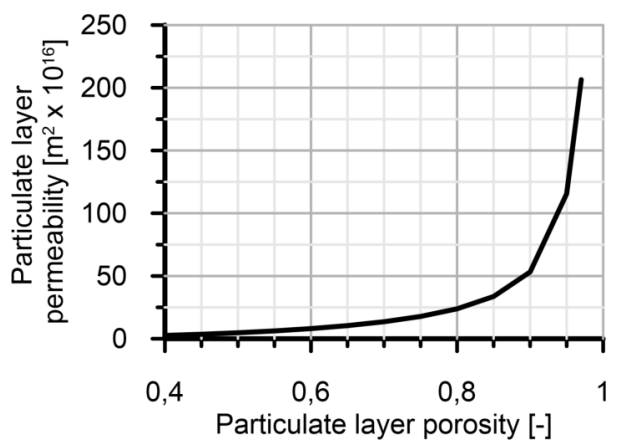

Figure 8. Particulate layer permeability as a function of the porosity.

Based on these magnitudes, the resulting pressure drop is finally defined by the filtration velocity. Figure $9 \mathrm{a}$ shows the filtration velocity profile along the inlet channel for a particular onset of the soot mass distribution $\left(\delta_{p l}=0.11 \mathrm{~m}\right)$ as a function of the particulate layer porosity after the first water injection. As the porosity decreases, the filtration velocity gets reduced in the initial inlet channel region. However, the filtration velocity is higher for low porosities in the rear end region. The flow tends to accumulate in the rear end of the inlet channel increasing the gas pressure because of the lower permeability related to low porosity. As a consequence, more mass flow passes across the thicker particulate layer region at higher velocity when the porosity decreases, thus leading to higher pressure drop. Complementarily, the filtration velocity profile for a particular porosity $\left(\varepsilon_{p l}=0.75\right)$ is represented in Figure $9 \mathrm{~b}$ as a function of the soot mass distribution onset. In this case, the filtration velocity gets reduced in the thin particulate layer region as the onset is moved back. Despite an intermediate region with the highest filtration velocity, it gets the minimum value also in the rear end, where the particulate layer has the maximum thickness. This kind of profile leads progressively 
to the almost linear pressure drop decrease shown in Figure 7 as the soot mass distribution onset is moved back.
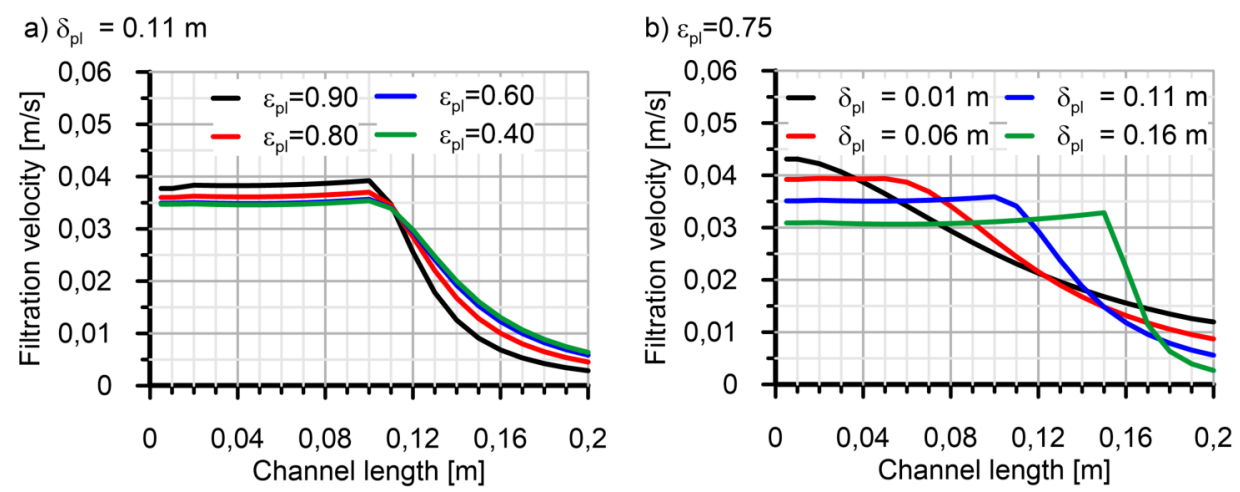

Figure 9. Filtration velocity profile as a function of the soot mass distribution onset and the particulate layer porosity after the first water injection event in DPF \#A.

Several combinations of values of particulate layer porosity and onset of the soot mass distribution provide the experimental pressure drop, i.e., the white line represented in the plots of Figure 6. This is due to the influence of these variables on filtration velocity and particulate layer permeability and thickness. Figure 10 represents a set of filtration velocity profiles determined by combinations of particulate layer porosity and the onset of soot mass distribution that reproduce the experimental pressure drop after every water injection event. In all cases, the compaction of the particulate layer must be accompanied by moving back the soot mass distribution since it leads to lower filtration velocity both in the thin layer region and in the rear end region, reducing the length of the transition from fast to slow velocities. This trend is more apparent as the amount of soot and the number of injections increase, since the soot is progressively dragged towards the rear end of the inlet channels.
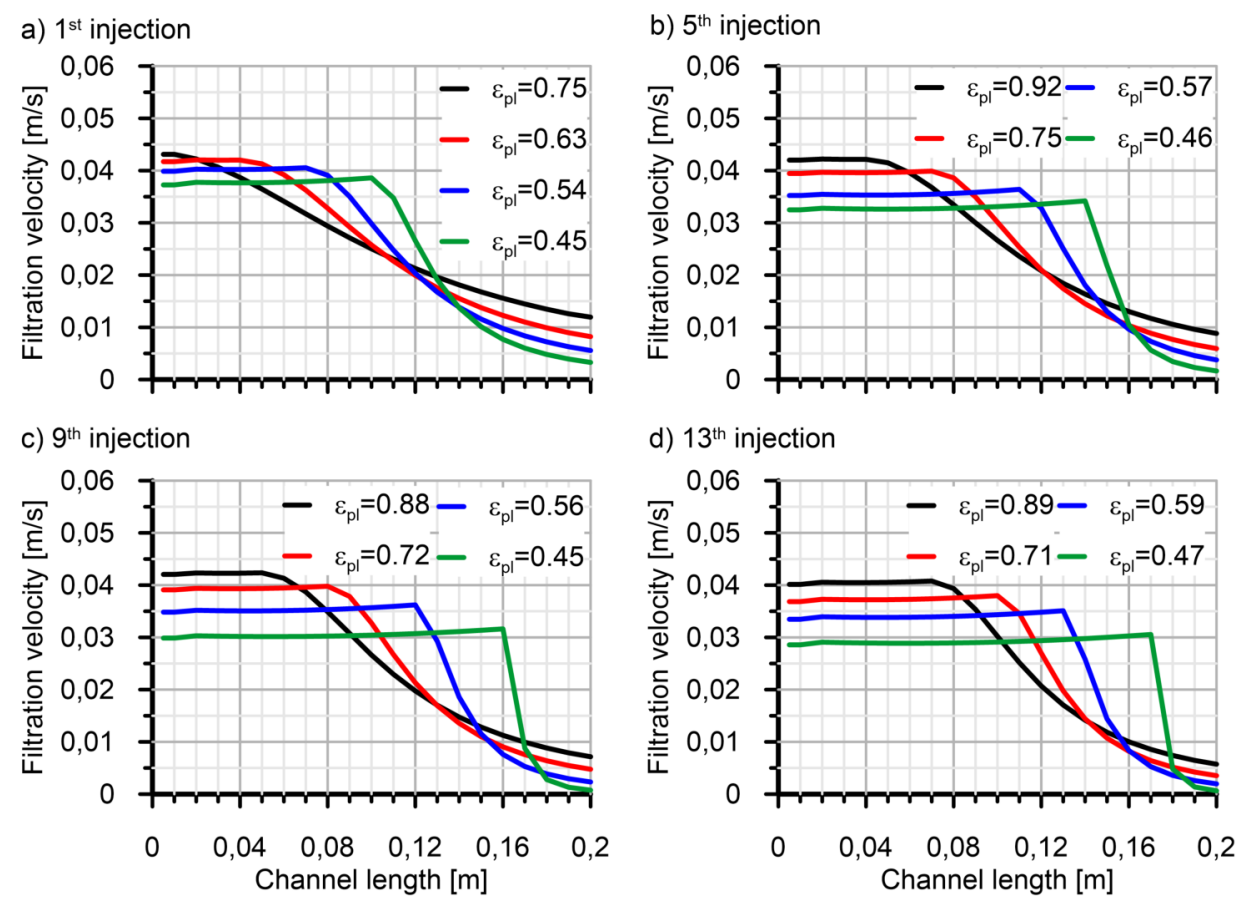

Figure 10. Filtration velocity profiles for different soot mass distribution onsets and particulate layer porosities providing the experimental pressure drop after every modeled injection event in DPF \#A. 
The analysis of the pressure drop after the water injection events provides general trends on the change of the particulate layer properties. In order to describe with higher detail its characteristics after every injection, several pairs of particulate layer porosity and soot mass distribution onset were selected to model the soot loading process following the injection event. Figure 11 represents the cases for the first and the 13th water injections. As shown in (a), the slope of the pressure drop after the first water injection is very sensitive to the properties of the particulate layer. In fact, the best fitting for the soot loading process is obtained for the case of no effects on the particulate layer porosity, whose reference value before injection is 0.65 , just a minimum drag of the particulate layer with an onset of the soot mass distribution in $0.045 \mathrm{~m}$ being required. Shorter drag would have minor effects on the pressure drop increasing rate, but requiring higher porosity of the particulate layer than baseline. By contrast, noticeable drag of the particulate layer after the first injection would require great compaction of the particulate layer, leading to small porosity values and to an excessive slope of the pressure drop increase as a function of the soot loading. As the number of injections increases, the slope of the pressure drop loss sensitivity to the particulate layer properties since the onset of the soot mass distribution increases for all possible porosities. As shown in the 13th water injection, in which the effectiveness of the injection process is limited, the onset of the soot mass distribution is within a small range. Nevertheless, it is interesting to note that there is still a valid solution for the baseline porosity, which confirms that the compaction effect of the water can be considered negligible.
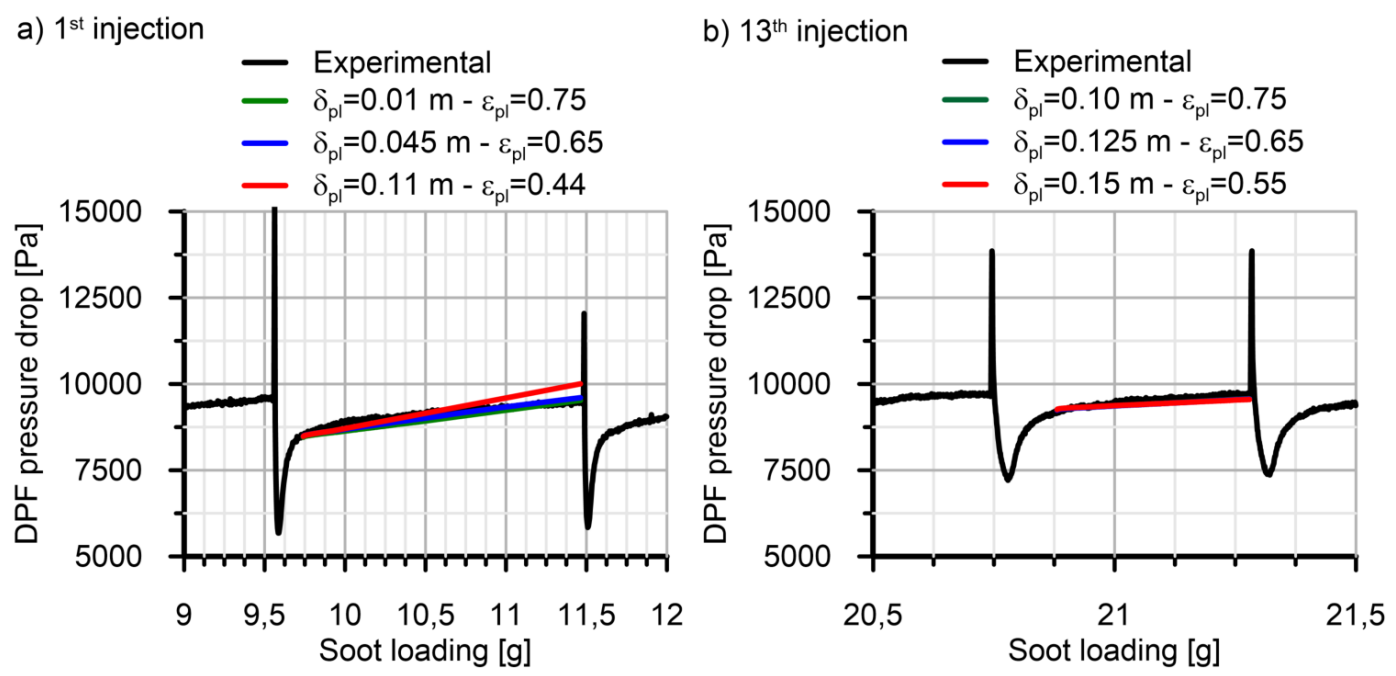

Figure 11. Influence of the soot mass distribution onset and the particulate layer porosity on the rate of increase of the pressure drop after water injection events in DPF \#A.

To finish the analysis of the pressure drop reduction causes, Figure 12 represents the obtained results for the first and 13th water injections imposing a linear soot mass distribution instead of a parabolic profile. As observed, all of the general trends previously described can be considered independent of the kind of soot mass distribution law defining the particulate layer. The main difference is related to the onset of the soot mass distribution, which should be delayed in the case of a linear distribution. This is why this kind of soot distribution imposes, for a particular onset, less soot moved towards the rear end in comparison to a parabolic distribution. Nevertheless, the order of magnitude of the solutions is very similar and proves that a lumped representation of the inlet channels cross-section provides good accuracy to understand the mechanism leading to pressure drop reduction after pre-DPF water injection. 

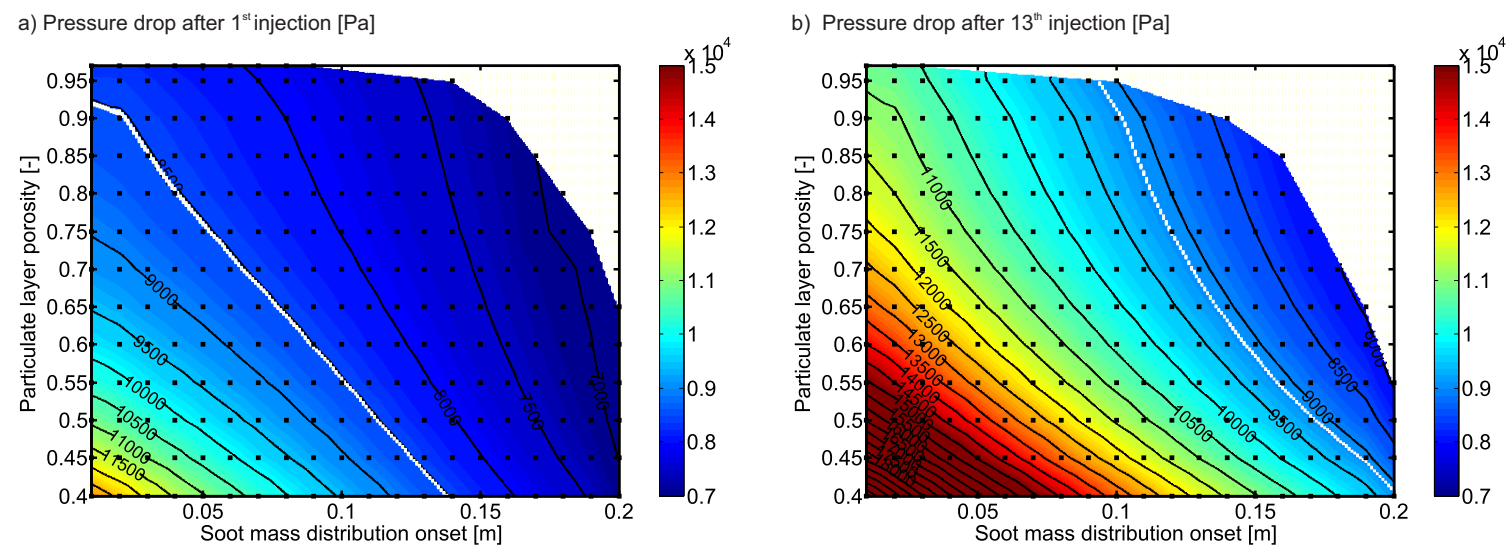

Figure 12. DPF pressure drop as a function of the particulate layer porosity and the soot mass distribution onset in DPF \#A imposing a linear soot mass distribution.

\subsection{Filtration Efficiency and Regeneration}

Experimental data confirmed that the use of pre-DPF water injection does not affect the filtration efficiency of the DPF [36], which was between $99.35 \%$ and $99.85 \%$ (number-based filtration efficiency) during the soot loading process shown in Figure 2. According to the theoretical and visualization results shown in Section 4.1, this behavior can be justified based on the lack of variation of the soot penetration into the porous wall, keeping a saturated portion that acts as a barrier filter of high collection efficiency. It ensures high filtration efficiency in the entrance region before the onset of the particulate layer. In addition, the sparse thin particulate layer along the inlet channels and its concentration towards the end region also contribute to ensure the filtration performance of the DPF. Thus, the theoretical mass-based filtration efficiency is over $99.95 \%$ for all considered particulate layer characteristics, as shown in Figure 13 for operating conditions after the first and 13th water injections.
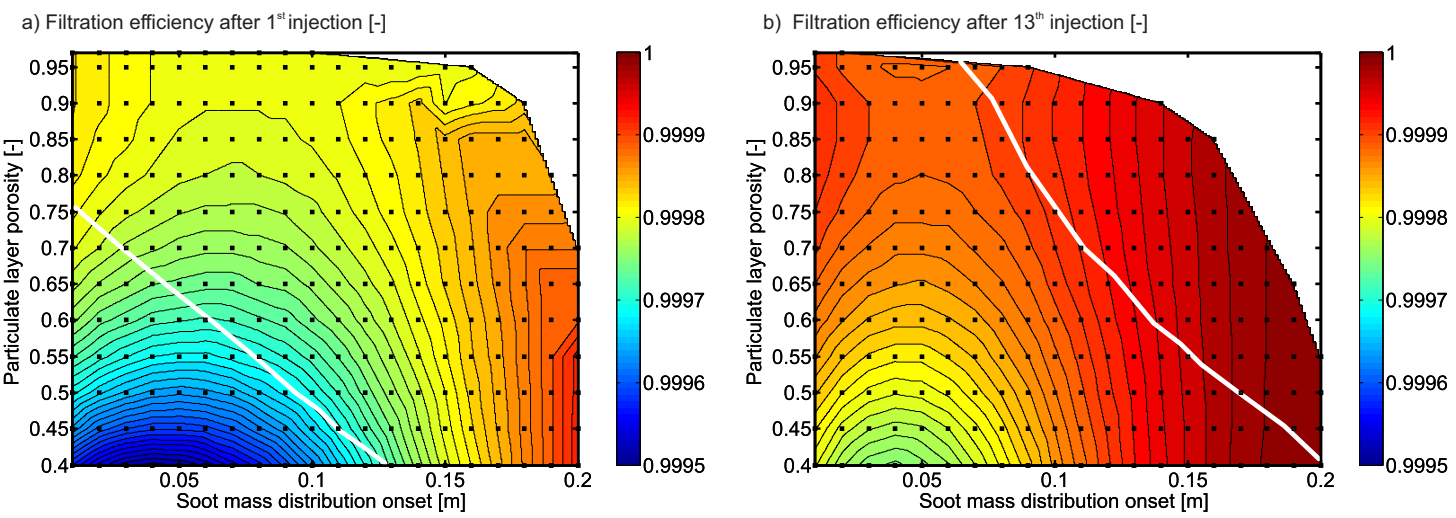

Figure 13. Filtration efficiency as a function of the particulate layer porosity and the soot mass distribution onset after different injection events.

With respect to the regeneration behavior, previous works showed the lack of relevant influence of pre-DPF water injection on passive and active regeneration processes based on pressure drop and outlet gas temperature evolution [12]. In this work, an active regeneration process have been modeled. Figure 14 shows in (a) the experimental and modeled pressure drop variation along the active regeneration, while (b) is devoted to the temperature fashion. In both tests (baseline and applying consecutive water injections), the DPF was previously loaded up to $60 \mathrm{~g}$. After the soot loading, two consecutive NEDCs were performed before active regeneration. Details on the soot loading can be consulted in [12]. At the beginning of the regeneration, lower pressure drop in the case of the soot loading applying pre-DPF water injections can be clearly observed. This is even 
obtained with higher temperature along the monolith (higher outlet gas temperature), whose effect is the pressure drop increase (lower gas density). The interest for these tests is in fact such a difference in outlet temperature at the beginning of the regeneration. The outlet gas temperature is higher in the case of the DPF sample subjected to water injections. This is due to the fact that a longer thermal stabilization period took place in this case before the regeneration started. Being that the inlet gas temperature is equal during the two regenerations and the outlet one higher in the pre-DPF water injection sample, a faster regeneration process is expected for this last case. This result is also deduced from the pressure drop dynamics, which is properly predicted by the model for both tests. The temperature peak at the DPF outlet is almost equal in both tests, obtaining also consistent modeled results. The gas temperature within the monolith, which is shown in Figure 15, is also very similar in both regenerations. The temperature increase is faster in the pre-DPF water injection case mainly due to higher initial temperature. Nevertheless, this situation does not promote hot spots' appearance keeping the maximum temperature in the same order of magnitude as the baseline regeneration.
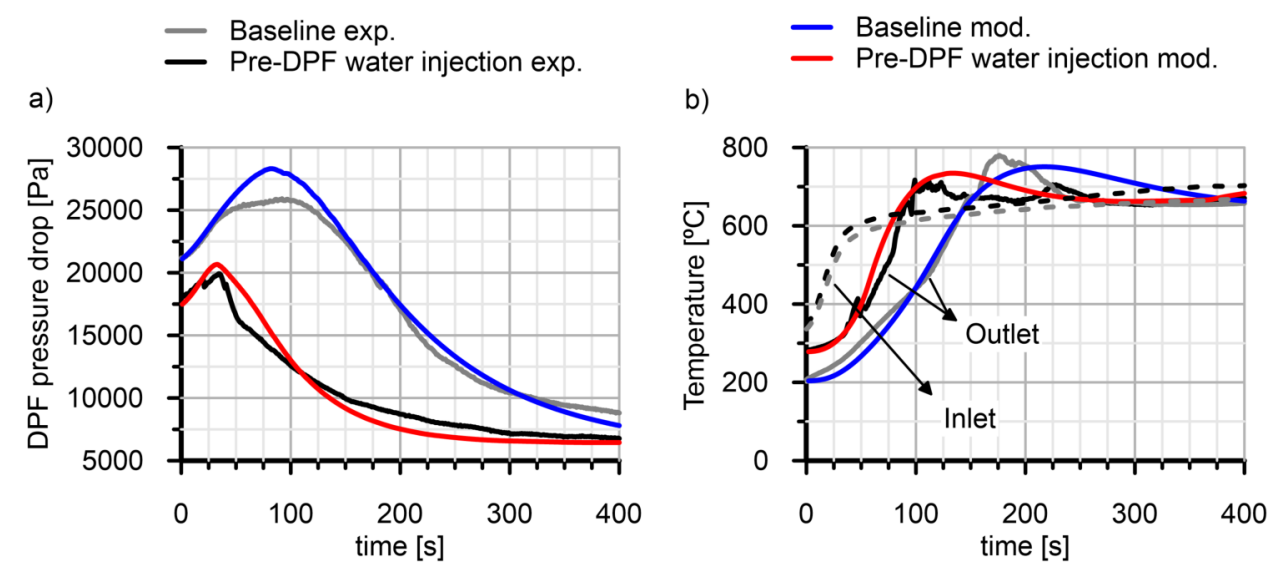

Figure 14. Caption can be rewritten as: Comparison between experimental and modeled (a) DPF pressure drop and $(\mathbf{b})$ gas temperature during active regeneration: baseline vs. pre-DPF water injection.
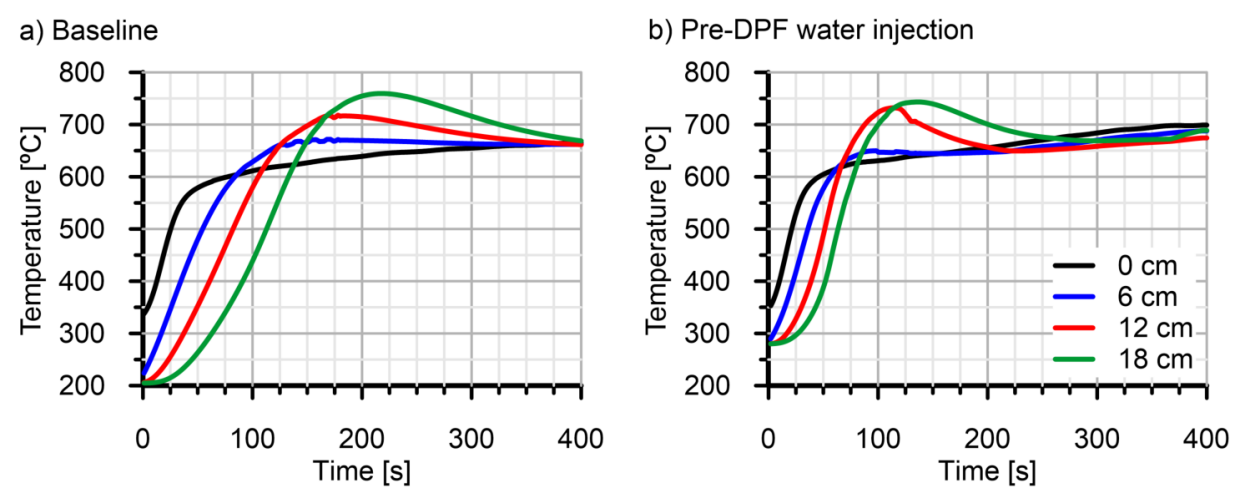

Figure 15. Gas temperature evolution during the regeneration process in different locations of the monolith.

Nevertheless, a more detailed analysis of the modeling results provides interesting insights. Figure 16a shows the evolution of the DPF soot mass during the regeneration process. The soot mass depletion rate is higher in the case of the pre-DPF water injection during the first seconds of the regeneration, but it gets progressively slower. In fact, the amount of soot still accumulated into the DPF in the case of the pre-DPF water injection is clearly higher from $200 \mathrm{~s}$ on. Therefore, the fast reduction in pressure drop during this test can be only explained by non-uniformity in the soot depletion rate along the monolith. Figure $16 \mathrm{~b}$ shows the variation in particulate layer thickness during the regeneration process in different channels' locations. In the baseline regeneration, the change in particulate layer 
thickness follows the same dynamics at all distances observing just some delay towards the monolith rear end governed by the thermal transient. This is confirmed by the soot depletion rate and the $\mathrm{O}_{2}$ outlet mass fraction shown in (c) and (d) of Figure 16, respectively. This behavior is governed by the filtration velocity, which is shown in Figure 16e. It is very homogenous along the inlet channels, thus leading to similar gas mass flow and dwell time.

a)

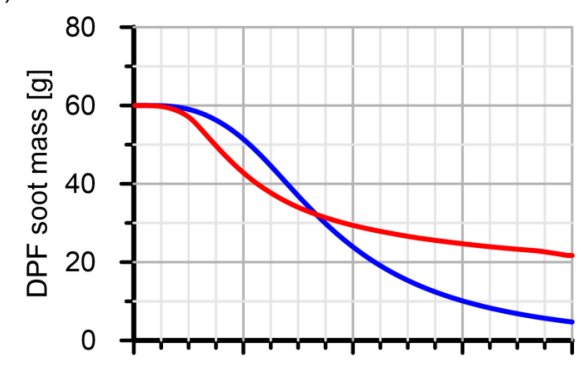

c)

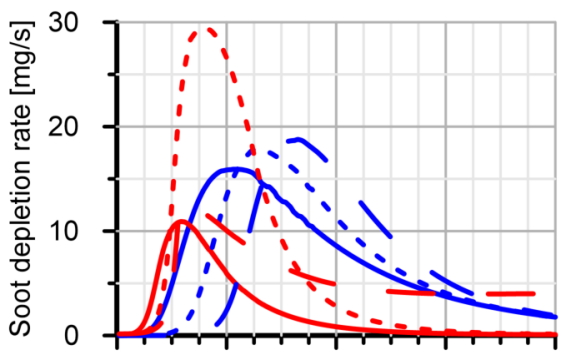

e)

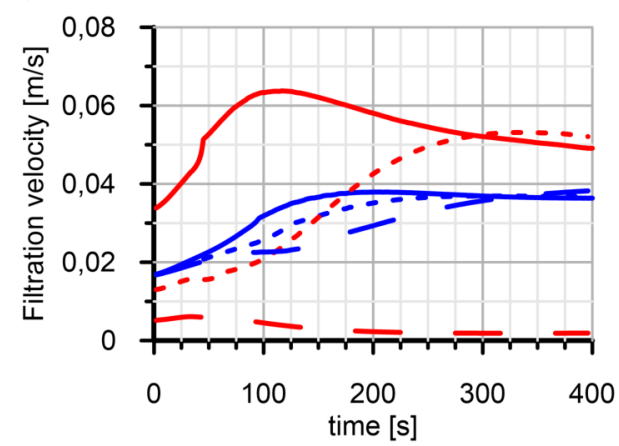

b)

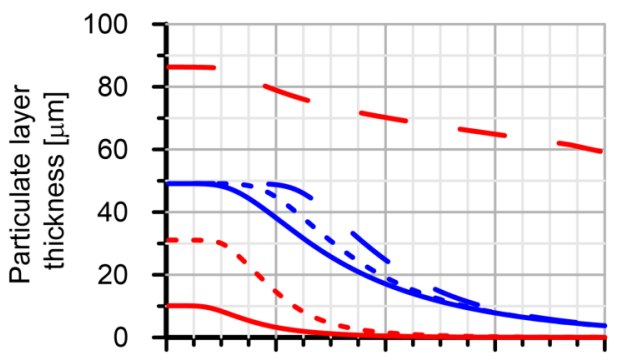

d)

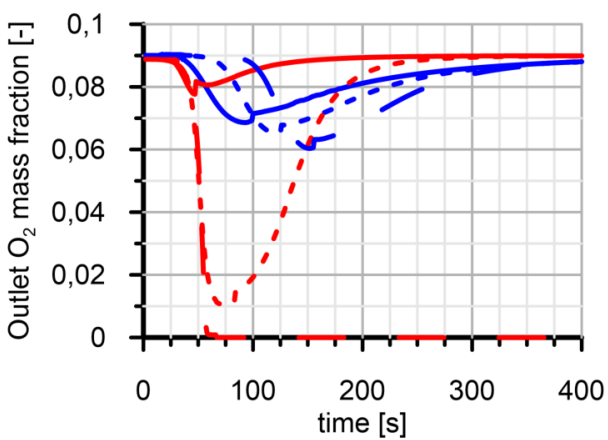

- Baseline

- Pre-DPF water injection

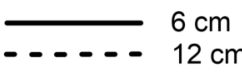

$12 \mathrm{~cm}$

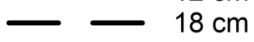

Figure 16. Comparison of the evolution of (a) soot mass; (b) particulater layer thickness; (c) soot depletion rate; (d) outlet $\mathrm{O} 2$ mass fraction and (e) filtration velocity during active regeneration: baseline vs. pre-DPF water injection.

Nevertheless, the different initial particulate layer thickness in pre-DPF water injection case conditions its subsequent reduction dynamics along the regeneration process. Figure $16 \mathrm{~b}$ confirms how the particulate layer reaches a thin thickness and disappears very fast up to the intermediate inlet channel region. It explains the fast pressure drop reduction inducing to conclude that the regeneration is close to the end. However, the oxidation of soot in the rear end region, where most of the soot has been dragged, is very slow. It is interesting to note that according to Figure 16c, the depletion rate is very similar in the inlet and rear end region, being maximum in the middle region. This is explained by the filtration velocity. It is very high at $6 \mathrm{~cm}$ from the very beginning because of the thin particulate layer. Consequently, the soot depletion rate is determined by a reduced dwell time, but high gas temperature and $\mathrm{O}_{2}$ concentration (outlet mass fraction shown in Figure 16d). As a result, the soot depletion rate is high enough to quickly remove the particulate layer. As the particulate layer is progressively removed along the inlet channels, the filtration velocities tend to coincide, as deduced 
from the analysis of the filtration velocity at $6 \mathrm{~cm}$ and $12 \mathrm{~cm}$. Compared to these distances, the soot depletion rate in the rear end $(18 \mathrm{~cm})$, where the particulate layer is thicker, is as high as at $6 \mathrm{~cm}$. However, the filtration velocity is very small. It provides high dwell time, favoring soot oxidation, but the small total amount of $\mathrm{O}_{2}$ mass (despite high inlet concentration) produced is all consumed, thus limiting the soot depletion rate. This behavior is more penalized as soot is oxidized in the inlet and middle channel regions because the flow tends to go across the porous wall in these sections. Consequently, the filtration velocity is further reduced in the channel rear end, slowing down the final regeneration phase.

\section{Conclusions}

A modeling work conducted on the understanding of the causes of pre-DPF water injection effects on wall-flow DPF pressure drop, filtration and regeneration response has been presented. A one-dimensional wall-flow DPF model has been applied to explore how the soot mass distribution in the particulate layer formed on the inlet channels walls and the porosity of the particulate layer influence on pressure drop. Good agreement has been found between experimental data, optical visualization of the monolith channels and modeling of pressure drop. In fact, the modeling results of the pressure drop after pre-DPF water injections events have confirmed that the soot mass on the particulate layer must be moved back as a required condition to reduce the DPF pressure drop.

Although the onset of the soot mass distribution is dependent on the particulate layer porosity, the modeling of the soot loading after every injection event has demonstrated that the particulate layer compaction has a negligible impact. Likewise, parabolic and linear soot mass distribution profiles have been computed obtaining just minor changes to the onset of the soot mass distribution. The main outcomes on the mechanism governing the pressure drop reduction are not sensitive to this parameter.

In agreement with experimental data obtained in previous works, modeling results indicate that the filtration efficiency is not modified by pre-DPF water injection. The reason lies in the fact that the porous wall is kept saturated acting as a barrier filter. However, the conclusions on the regeneration dynamics during active processes obtained from experimental data have been contradicted by the modeled results. The results obtained in this work evidence that the soot depletion rate when the DPF has been subjected to water injection is non-uniform along the inlet channels, in contrast to the baseline case. In fact, the entering and middle regions are quickly regenerated. This makes the pressure drop rapidly decrease. However, the rear end region of the inlet channels behaves as a plug end, the filtration velocity (mass flow) being very small along this porous wall region. Consequently, the soot oxidation gets mass transfer limited, leading to a slower regeneration end phase than the baseline operating conditions. This behavior points out that optimization of active regeneration strategies should be required in order to take maximum advantage from pre-DPF water injection benefits.

Beyond particular concerns on pre-DPF water injection, the results obtained in this study also contribute to highlight the importance of the soot loading process and how engine operation history can determine the soot structure (recurrent engine stops with water condensation, highly dynamic engine operation, etc.). It would explain pressure drop variability under the same operating conditions, which can cover up the real DPF state and lead to additional engine fuel consumption penalty and substrate durability issues, especially when pressure drop-based control is considered.

Acknowledgments: This work has been partially supported by the Spanish Ministry of Economy and Competitiveness through Grant No. TRA2016-79185-R. Additionally, the Ph.D. student Enrique José Sanchis has been funded by a grant from Universitat Politècnica de València with the reference FPI-2016-S2-1355. This support is gratefully acknowledged by the authors.

Author Contributions: All authors discussed and agreed on the contents of the manuscript. Pedro Piqueras coordinated the work defining the objectives of the experimental and modeling tasks, guiding the technical discussion of the results and manuscript writing. Enrique José Sanchis contributed to the design of the theoretical study, performed the calculations, analyzed the results and collaborated in the manuscript preparation. José Ramón Serrano and Vicente Bermúdez discussed the results, contributed to manuscript writing and provided technical guidance in experimental phases from the first stages of the project development. 
Conflicts of Interest: The authors declare no conflict of interest. The founding sponsors had no role in the design of the study; in the collection, analyses or interpretation of data; in the writing of the manuscript; nor in the decision to publish the results.

\section{Abbreviations}

The following abbreviations are used in this manuscript:

$\begin{array}{ll}A_{f} & \text { filtration area } \\ C_{g a s} & \text { gas concentration } \\ d_{c} & \text { collector unit diameter } \\ d_{c e l l} & \text { cell unit diameter } \\ d_{p} & \text { mean pore diameter } \\ D & \text { diameter } \\ e_{0} & \text { specific stagnation internal energy } \\ E_{f, w} & \text { porous wall filtration efficiency } \\ f_{w} & \text { saturated fraction of porous wall thickness } \\ F & \text { area } \\ F_{w} & \text { momentum transfer coefficient for square channels } \\ h_{0} & \text { specific stagnation enthalpy } \\ k & \text { permeability } \\ k_{n} & \text { kinetic constant of reagent } n \\ L & \text { channel length } \\ m_{S} & \text { soot mass } \\ M_{C} & \text { carbon molecular weight } \\ p & \text { pressure } \\ q & \text { heat per unit of time and mass } \\ S_{p} & \text { specific surface } \\ t & \text { time } \\ u & \text { velocity } \\ u_{w} & \text { filtration velocity } \\ w_{p l} & \text { particulate layer thickness } \\ w_{w} & \text { porous wall thickness } \\ x & \text { axial dimension } \\ X & \text { molar fraction } \\ Y & \text { mass fraction } \\ z & \text { tangential dimension } \\ & \end{array}$

Greek letters

$\begin{array}{ll}\alpha & \text { honeycomb cell size } \\ \alpha_{n} & \text { stoichiometric coefficient of reagent } n \\ \delta_{p l} & \text { soot mass distribution onset } \\ \Delta & \text { variation } \\ \varepsilon & \text { porosity } \\ \eta_{D R I} & \text { single sphere filtration efficiency } \\ \mu & \text { dynamic viscosity } \\ \rho & \text { gas density } \\ \rho_{C} & \text { carbon density } \\ \rho_{s, w} & \text { soot packing density inside the porous wall } \\ \sigma & \text { cell density } \\ \chi & \text { shape factor }\end{array}$




$\begin{array}{ll}\text { Subscripts } & \\ \text { cell } & \text { referred to the cell unit } \\ e & \text { effective } \\ \text { in } & \text { referred to the inlet channel } \\ j & \text { channel type } \\ n & \text { reagent }\left(\mathrm{O}_{2}, \mathrm{NO}_{2}\right) \\ \text { out } & \text { referred to the outlet channel } \\ p l & \text { referred to the particulate layer } \\ r e g & \text { referred to the regeneration } \\ w & \text { referred to the porous wall } \\ w_{0} & \text { referred to the clean porous wall }\end{array}$

Abbreviations

$\begin{array}{ll}\text { 2LW } & \text { Two-step Lax and Wendroff method } \\ \text { DOC } & \text { Diesel Oxidation Catalyst } \\ \text { DPF } & \text { Diesel Particulate Filter } \\ \text { EEPS } & \text { Engine Exhaust Particle Sizer } \\ \text { FCT } & \text { Flux-Corrected Transport } \\ \text { HSDI } & \text { High-Speed Direct Injection } \\ \text { MoC } & \text { Method of Characteristics } \\ \text { NEDC } & \text { New European Driving Cycle } \\ \text { SCF } & \text { Stokes-Cunningham Factor } \\ \text { SCR } & \text { Selective Catalytic Reduction } \\ \text { SCRF } & \text { Selective Catalytic Reduction Filter } \\ \text { SEM } & \text { Scanning Electron Microscope }\end{array}$

\section{References}

1. Johnson, T.V. Review of vehicular emissions trends. SAE Int. J. Engines 2015, 8, 1152-1167.

2. Bermúdez, V.; Serrano, J.R.; Piqueras, P.; García-Afonso, O. Assessment by means of gas dynamic modeling of a pre-turbo diesel particulate filter configuration in a turbocharged HSDI diesel engine under full-load transient operation. Proc. Inst. Mech. Eng. D J. Automob. Eng. 2011, 225, 1134-1155.

3. Subramaniam, M.N.; Joergl, V.; Keller, P.; Weber, O.; Toyoshima, T.; Vogt, C.D. Feasibility Assessment of a pre-turbo after-treatment system with a 1D modeling approach. SAE Tech. Pap. 2009, doi:10.4271/2009-01-1276.

4. Luján, J.M.; Bermúdez, V.; Piqueras, P.; García-Afonso, O. Experimental assessment of pre-turbo aftertreatment configurations in a single stage turbocharged Diesel engine. Part 1: Steady-state operation. Energy 2015, 80, 599-613.

5. Luján, J.M.; Serrano, J.R.; Piqueras, P.; García-Afonso, O. Experimental assessment of a pre-turbo aftertreatment configuration in a single stage turbocharged Diesel engine. Part 2: Transient operation. Energy 2015, 80, 614-627.

6. Lee, J.H.; Michael, J.; Brown, D.B. Evaluation of Cu-based SCR/DPF technology for diesel exhaust emission control. SAE Int. J. Fuels Lubr. 2009, 1, 96-101.

7. Watling, T.C.; Ravenscroft, M.R.; Avery, G. Development, validation and application of a model for an SCR catalyst coated diesel particulate filter. Catal. Today 2012, 188, 32-41.

8. Marchitti, F.; Nova, I.; Tronconi, E. Experimental study of the interaction between soot combustion and NH3-SCR exhaust reactivity over a Cu-Zeolite SDPF catalyst. Catal. Today 2016, 217, 110-118.

9. Konstandopoulos, A.G.; Kostoglou, M. Analysis of asymmetric and variable cell geometry wall-flow particulate filters. SAE Int. J. Fuels Lubr. 2014, 7, 489-495.

10. Bollerhoff, T.; Markomanolakis, I.; Koltsakis, G. Filtration and regeneration modeling for particulate filters with inhomogeneous wall structure. Catal. Today 2012, 188, 24-31.

11. Iwata, H.; Konstandopoulos, A.G.; Nakamura, K.; Ogiso, A.; Ogyu, K.; Shibata, T.; Ohno, K. Further experimental study of asymmetric plugging layout on DPFs: Effect of Wall thickness on pressure drop and soot oxidation. SAE Tech. Pap. 2015, doi:10.4271/2015-01-1016. 
12. Serrano, J.R.; Bermúdez, V.; Piqueras, P.; García-Afonso, O. Pre-DPF water injection technique for loaded DPF pressure drop reduction and control. Appl. Energy 2015, 140, 234-245.

13. Serrano, J.R.; Bermúdez, V.; Piqueras, P.; Angiolini, E. Application of pre-DPF water injection technique for pressure drop limitation. SAE Tech. Pap. 2015, doi:10.4271/2015-01-0985.

14. Wang, Y.; Wong, V.; Sappok, A.; Munnis, S. The sensitivity of DPF performance to the spatial distribution of ash inside DPF inlet channels. SAE Tech. Pap. 2013, doi:10.4271/2013-01-1584.

15. Sappok, A.; Govani, I.; Kamp, C.; Wang, Y.; Wong, V. In-situ optical analysis of ash formation and transport in diesel particulate filters during active and passive regeneration processes. SAE Int. J. Fuels Lubr. 2013, 6, 336-349.

16. Torregrosa, A.J.; Serrano, J.R.; Arnau, F.J.; Piqueras, P. A fluid dynamic model for unsteady compressible flow in wall-flow Diesel particulate filters. Energy 2011, 36, 671-684.

17. OpenWAM Website. CMT-Motores Tèrmicos (Universitat Politècnica de València). 2017. Available online: www.openwam.org (accessed on 15 January 2017).

18. Galindo, J.; Serrano, J.R.; Arnau, F.J.; Piqueras, P. Description and analysis of a one-dimensional gas-dynamic model with Independent Time Discretization. In Proceedings of the ASME Internal Combustion Engine Division 2008 Spring Technical Conference ICES 2008, Chicago, IL, USA, 27-30 April 2008.

19. Lax, P.; Wendroff, B. Systems of conservation laws. Commun. Pure Appl. Math. 1964, 17, 381-398.

20. Serrano, J.R.; Arnau, F.J.; Piqueras, P.; García-Afonso, O. Application of the two-step Lax\&Wendroff-FCT and the CE-SE method to flow transport in wall-flow monoliths. Int. J. Comput. Math. 2014, 91, 71-84.

21. Benson, R.S. The Thermodynamics and Gas Dynamics of Internal-Combustion Engines; Clarendon Press: New York, NY, USA, 1982; Volume 1.

22. Desantes, J.M.; Serrano, J.R.; Arnau, F.J.; Piqueras, P. Derivation of the method of characteristics for the fluid dynamic solution of flow advection along porous wall channels. Appl. Math. Model. 2012, 36, 3144-3152.

23. Serrano, J.R.; Arnau, F.J.; Piqueras, P.; Garcia-Afonso, O. Packed bed of spherical particles approach for pressure drop prediction in wall-flow DPFs (diesel particulate filters) under soot loading conditions. Energy 2013, 58, 644-654.

24. Murtagh, M.; Sherwood, D.; Socha, L. Development of a diesel particulate filter composition and its effect on thermal durability and filtration performance. SAE Tech. Pap. 1994, doi:10.4271/940235.

25. Fino, D.; Russo, N.; Millo, F.; Vezza, D.; Ferrero, F.; Chianale, A. New tool for experimental analysis of diesel particulate filter loading. Top Catal. 2009, 52, 13-20.

26. Konstandopoulos, A.G.; Johnson, J.H. Wall-flow diesel particulate filters-Their pressure drop and collection efficiency. SAE Tech. Pap. 1989, doi:10.4271/890405.

27. Lapuerta, M.; Ballesteros, R.; Martos, F. A method to determine the fractal dimension of diesel soot agglomerates. J. Coll. Interface Sci. 2006, 303, 149-158.

28. Serrano, J.R.; Climent, H.; Piqueras, P.; Angiolini, E. Filtration modeling in wall-flow particulate filters of low soot penetration thickness. Energy 2016, 112, 883-888.

29. Logan, B.E.; Jewett, D.G.; Arnold, R.G.; Bouwer, E.J.; O'Melia, C.R. Clarification of clean-bed filtration models. J. Environ. Eng. 1995, 121, 869-873.

30. Koltsakis, G.C.; Stamatelos, A.M. Modes of catalytic regeneration in Diesel particulate filters. Ind. Eng. Chem. 1997, 36, 4155-5165.

31. Bisset, E.J. Mathematical model of the thermal regeneration of a wall-flow monolith diesel particulate filter. Chem. Eng. Sci. 1984, 39, 1233-1244.

32. Galindo, J.; Serrano, J.R.; Piqueras, P.; García-Afonso, O. Heat transfer modeling in honeycomb wall-flow diesel particulate filters. Energy 2012, 43, 201-213.

33. Payri, F.; Broatch, A.; Serrano, J.R.; Piqueras, P. Experimental-theoretical methodology for determination of inertial pressure drop distribution and pore structure properties in wall-flow diesel particulate filters (DPFs). Energy 2011, 36, 6731-6744.

34. Angiolini, E. Contribution to the Understanding of Filtration and Pressure Drop Phenomena in Wall-Flow DPFs. Ph.D. Thesis, Universitat Politècnica de València, València, Spain, 2017. 
35. Konstandopoulos, A.G.; Skaperdas, E.; Masoudi, M. Microstuctural properties of soot deposits in diesel particulate traps. SAE Tech. Pap. 2002, doi:10.4271/2002-01-1015.

36. Bermúdez, V.; Serrano, J.R.; Piqueras, P.; Campos, D. Analysis of the influence of pre-DPF water injection technique on pollutants emission. Energy 2015, 89, 778-792. 